\title{
Measurement and analysis of informatization level of manufacturing
}

\author{
industries \\ Xiao-dong $\mathrm{Yu}$ \\ Beijing JiaoTong University, China \\ Corresponding author: Xiao-dong Yu, Master, yxd450658621@163.com
}

\begin{abstract}
By establishing industry informatization index system, the informatization level of the industry was measured by principal component analysis with the panel data of manufacturing industry from 2006 2014. It is obvious that the informatization level of industries was significantly different. Most of the industries showed the growth trend in the research time span. However, different industries have different characteristics. Finally related development strategies according to the research results are put forward.
\end{abstract}

Key words: informatization level; manufacturing industries; principal component analysis

\section{Research background}

Manufacturing is always an important part of China's economy. In 2015, "Made in China 2025" put forward ten key development areas and new requirements for the development of manufacturing industries. The development in the new period requires higher technical innovation efficiency. At present, with the booming development of China's information industry, information technology is progressing and widely applied to various industries. The current economic development has entered the era of knowledge economy. High level of informatization is the important characteristic of knowledge economy. Under the new development mode of "Internet +", an industry which has more information can be better integrated with the Internet. However, informatization level of manufacturing industries in China is still in a middle position in the world. Informatization can influence the promotion of production, management and technological innovation of manufacturing industries. Construction of informatization is of great significance. 


\section{Literature review}

The concept of information originated in Japan in the 1960s. A theory was put forward from the perspective of the evolution of the social industrial structure. This new theory revealed the new development stage in Japan. In 1963, Japanese sociologist Tadao Umesao not only firstly put forward the "Information society" as the future of human society, but also showed the prospect of "Information Revolution" and outlined the blueprint of "Information Society" in the book Information Industry Theory ${ }^{1}$. The concept of informatization had been well known in the early 1990s because of the contribution of vice president Gore to the construction of "Information Superhighway ". This "new economy" that led to the high growth rate of the American economy and low inflation in 10 years gave the whole world a great inspiration ${ }^{2}$. Informatization made the information infrastructure the new pillar of the national economy. The informatization construction in China was started in the mid - 1980s, which was lagged behind developed countries. The information theory and informatization development level measurement theory and method were studied by many scholars. In 1997, the Information Work Leading Group of the State Council first proposed the definition of national informatization

Researchers have carried out a large number of empirical studies. Zheng Weiping (2001) made a comparative analysis of the degree of regional economic informatization ${ }^{3}$. Hu Xiaopeng (2003) compared the spatial difference of informatization development level, and classified the level of regional informatization development. The result revealed the regularity relationship that reflects the level of informatization and development ${ }^{4}$. In 2004, the National Information Evaluation Center issued the first Chinese enterprise informatization index system. This index system put forward the concept of "construction of informatization with benefits" for the first time. Enterprise informatization benchmarking library was needed to be established to constitute a basic database that can reflect the statistical regularity. This library can be used to accurately evaluate the level of enterprise informatization and the level of benefits. Wang Bin and Yu Dongyun(2004)calculate the level of informatization development in China in recent ten years according to the information integration index model ${ }^{5}$. On this basis, the impact of informatization on the national economy and the three industries can be estimated. This research also found that the contribution of informatization to industrial growth is the largest. 


\section{Measurement of informatization level}

The quantitative measurement of informatization came from Fritz Machlup, an American economist. In his book “American Knowledge Production and Distribution”, he put forward the theory of informatization measurement. In 1977, American information economist Porat proposed an operable informatization measurement method. Porat considered that the development of the information economy is mainly composed of the development of two major information departments. One section concluded departments directly produce information and knowledge, and the other section concluded departments that consume information. In 2006 He Wei proposed industry informatization measurement methods and analyzed the development trend of the informatization of industries. This paper refers the informatization assessment method of He Wei (2006) ${ }^{6}$ and Han Xianfeng (2014) ${ }^{7}$ to establish an informatization index system for manufacturing industries, as shown in the Fig.1:

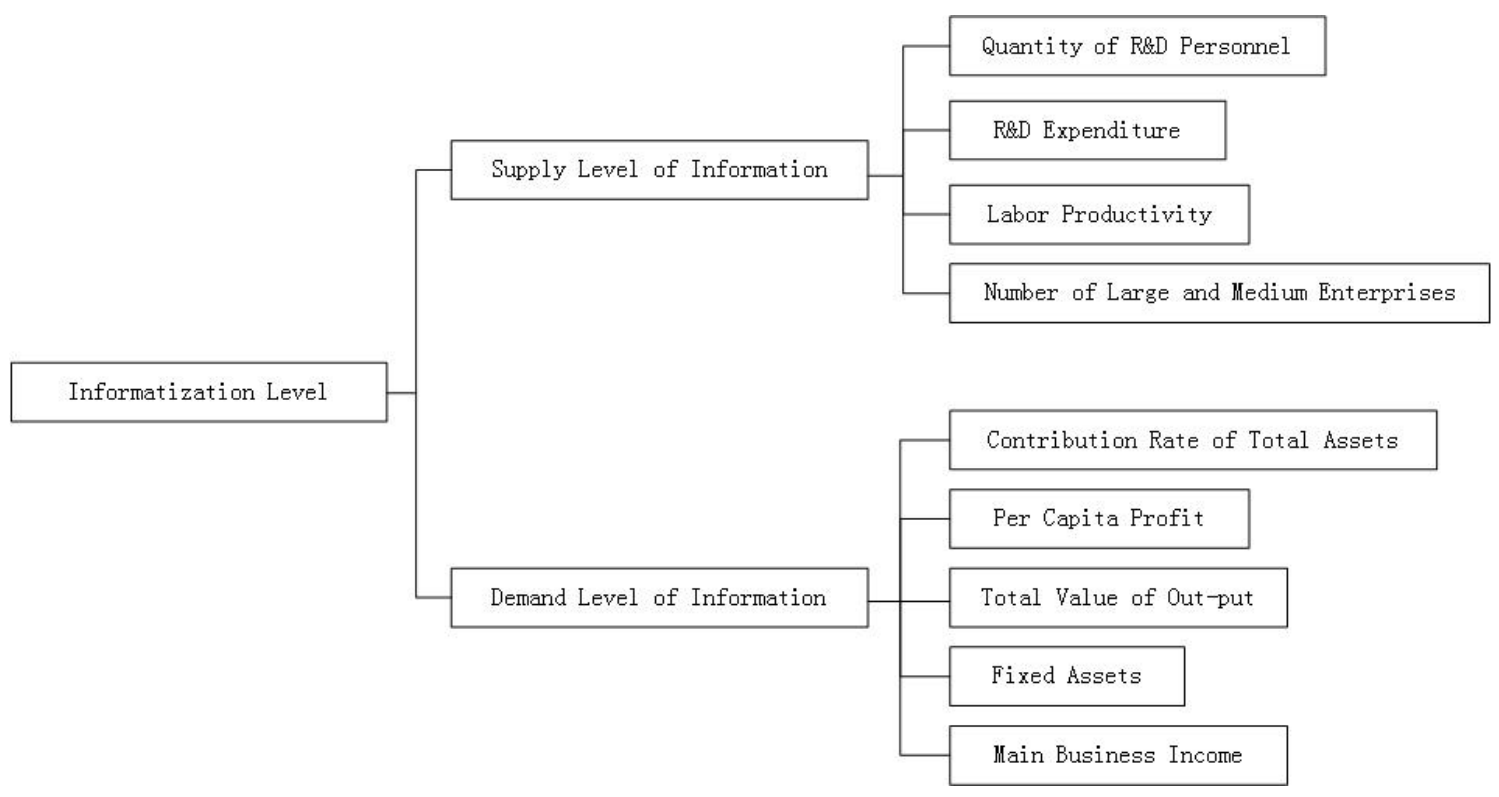

Fig. 1 -Informatization Index System

Principal Components Analysis is a commonly used method in the field of statistics. A group of possible correlated variables can be transformed into a set of linearly independent variables by orthogonal transformation, and the transformed group is called principal component. In many practical projects, in order to analyze the problem comprehensively, many variables (or factors ) related to this problem are proposed, since each variable reflects some information of this subject to varying degrees.

Data needed are sorted out according to China Statistical Yearbook 2006-2015, China Industrial Statistics Yearbook 2006-2015, China Statistical Yearbook on Science and 
Technology 2006-2015. Number the 27 manufacturing industries H1 to H27. By using Principal Components Analysis (PCA) through SPSS 19, we can get the following two tables.

Table 1 -Total Variance Explained

\begin{tabular}{|l|c|c|c|}
\hline \multirow{2}{*}{ Components } & & & \\
\cline { 2 - 4 } & & \% of Variance & Cumulative \% \\
\hline 1 & 5.081 & 56.451 & 56.451 \\
\hline 2 & 2.288 & 25.417 & 81.868 \\
\hline
\end{tabular}

Table 2 -Component Matrix

\begin{tabular}{|l|c|c|}
\hline \multirow{2}{*}{} & \multicolumn{2}{|c|}{ Component } \\
\cline { 2 - 3 } & 1 & 2 \\
\hline Zscore(x1) & 0.906 & 0.181 \\
\hline Zscore(x2) & 0.850 & 0.132 \\
\hline Zscore(x3) & -0.149 & 0.829 \\
\hline Zscore(x4) & 0.820 & -0.114 \\
\hline Zscore(x5) & -0.495 & 0.793 \\
\hline Zscore(x6) & -0.317 & 0.872 \\
\hline Zscore(x7) & 0.953 & 0.227 \\
\hline Zscore(x8) & 0.829 & 0.212 \\
\hline Zscore(x9) & 0.949 & 0.230 \\
\hline
\end{tabular}

Total score of principal components of the informatization index system can be regarded as a measurement of informatization level. According to the characteristic value and variance contribution rate in the table, the weight of each index is calculated.

$\mathrm{F} 1=\mathrm{X} 1 * 0.402+\mathrm{X} 2 * 0.377-\mathrm{X} 3 * 0.066+\mathrm{X} 4 * 0.323-\mathrm{X} 5 * 0.220-$

$\mathrm{X} 6 * 0.141+\mathrm{X} 7 * 0.423+\mathrm{X} 8 * 0.368+\mathrm{X} 9 * 0.421$

$\mathrm{F} 2=\mathrm{X} 1 * 0.120+\mathrm{X} 2 * 0.087+\mathrm{X} 3 * 0.548-$

$\mathrm{X} 4 * 0.075+\mathrm{X} 5 * 0.524+\mathrm{X} 6 * 0.576+\mathrm{X} 7 * 0.150+\mathrm{X} 8 * 0.140+\mathrm{X} 9 * 0.152$

$\mathrm{F}=(\mathrm{F} 1 * 56.451+\mathrm{F} 2 * 25.417) / 81.868$

So we can get the formula of total score of principal components:

$\mathrm{F}=\mathrm{X} 1 * 0.313+\mathrm{X} 2 * 0.28697+\mathrm{X} 3 * 0.124624+\mathrm{X} 4 * 0.227845+\mathrm{X} 5 * 0.011+\mathrm{X} 6 * 0.082+\mathrm{X} 7 * 0.34+\mathrm{X} 8$ $* 0.297+\mathrm{X} 9 * 0.337$

Normalized processing is also needed, then we can get the calculation method of informatization level:

$\mathrm{F}=\mathrm{X} 1 * 0.155+\mathrm{X} 2 * 0.142+\mathrm{X} 3 * 0.062+\mathrm{X} 4 * 0.113+\mathrm{X} 5 * 0.0054+\mathrm{X} 6 * 0.041+\mathrm{X} 7 * 0.168+\mathrm{X} 8 * 0.147$ $+\mathrm{X} 9 * 0.167$

In order to make the informatization level index positive, this paper refers the method used by Fan Gang (2003) to standardize the data. According to the above formula, we can calculate the informatization level index of manufacturing industries. 
Table 3 -Informatization Level of Manufacturing Industries

\begin{tabular}{|c|c|c|c|c|c|c|c|c|c|}
\hline & 2006 & 2007 & 2008 & 2009 & 2010 & 2011 & 2012 & 2013 & 2014 \\
\hline H1 & 0.2406 & 0.2559 & 0.3117 & 0.3284 & 0.3398 & 0.3748 & 0.4015 & 0.4218 & 0.4162 \\
\hline H2 & 0.1042 & 0.1069 & 0.1253 & 0.1246 & 0.1277 & 0.1401 & 0.1372 & 0.1405 & 0.1429 \\
\hline H3 & 0.1020 & 0.1046 & 0.1161 & 0.1116 & 0.1126 & 0.1238 & 0.1169 & 0.1142 & 0.1141 \\
\hline $\mathrm{H} 4$ & 0.1220 & 0.1282 & 0.1203 & 0.1536 & 0.1235 & 0.1319 & 0.1253 & 0.1194 & 0.1167 \\
\hline H5 & 0.3925 & 0.3814 & 0.3797 & 0.3491 & 0.3566 & 0.3716 & 0.3126 & 0.3080 & 0.2968 \\
\hline H6 & 0.1221 & 0.1246 & 0.1405 & 0.1815 & 0.1285 & 0.1620 & 0.1890 & 0.1841 & 0.1752 \\
\hline H7 & 0.0690 & 0.0681 & 0.0781 & 0.0692 & 0.0732 & 0.0866 & 0.0985 & 0.0945 & 0.0935 \\
\hline H8 & 0.0363 & 0.0356 & 0.0560 & 0.0505 & 0.0564 & 0.0798 & 0.0635 & 0.0668 & 0.0702 \\
\hline H9 & 0.0255 & 0.0236 & 0.0355 & 0.0271 & 0.0316 & 0.0381 & 0.0305 & 0.0308 & 0.0312 \\
\hline H10 & 0.1290 & 0.1250 & 0.1358 & 0.1133 & 0.1229 & 0.1271 & 0.1140 & 0.1030 & 0.0985 \\
\hline H11 & 0.0310 & 0.0265 & 0.0383 & 0.0270 & 0.0289 & 0.0306 & 0.0218 & 0.0267 & 0.0294 \\
\hline H12 & 0.0224 & 0.0159 & 0.0289 & 0.0178 & 0.0160 & 0.0216 & 0.0808 & 0.0880 & 0.0955 \\
\hline H13 & 0.2875 & 0.2893 & 0.2945 & 0.2869 & 0.3278 & 0.3306 & 0.3149 & 0.2957 & 0.2817 \\
\hline H14 & 0.5456 & 0.5722 & 0.6216 & 0.5801 & 0.6019 & 0.6795 & 0.6845 & 0.7088 & 0.7059 \\
\hline H15 & 0.1768 & 0.1656 & 0.1947 & 0.1955 & 0.1832 & 0.2147 & 0.2158 & 0.2266 & 0.2320 \\
\hline H16 & 0.0774 & 0.0807 & 0.0715 & 0.0553 & 0.0649 & 0.0728 & 0.0522 & 0.0436 & 0.0427 \\
\hline H17 & 0.2217 & 0.2226 & 0.2447 & 0.2272 & 0.2401 & 0.2486 & 0.2349 & 0.2385 & 0.2371 \\
\hline H18 & 0.3186 & 0.3215 & 0.3777 & 0.3680 & 0.3962 & 0.4487 & 0.4469 & 0.4717 & 0.4761 \\
\hline H19 & 0.6424 & 0.7122 & 0.7479 & 0.6128 & 0.6595 & 0.6650 & 0.6714 & 0.6355 & 0.5813 \\
\hline $\mathrm{H} 20$ & 0.2951 & 0.3159 & 0.3260 & 0.2863 & 0.3228 & 0.3499 & 0.3486 & 0.3507 & 0.3530 \\
\hline $\mathrm{H} 21$ & 0.1823 & 0.1897 & 0.2291 & 0.2146 & 0.2205 & 0.2335 & 0.2743 & 0.2843 & 0.2904 \\
\hline $\mathrm{H} 22$ & 0.4181 & 0.4110 & 0.4810 & 0.4653 & 0.4630 & 0.4907 & 0.4317 & 0.4416 & 0.4335 \\
\hline H23 & 0.2623 & 0.2646 & 0.3282 & 0.3215 & 0.3125 & 0.3504 & 0.3409 & 0.3519 & 0.3334 \\
\hline $\mathrm{H} 24$ & 0.6208 & 0.6627 & 0.6921 & 0.7129 & 0.7727 & 0.7663 & 0.7500 & 0.7671 & 0.8046 \\
\hline $\mathrm{H} 25$ & 0.5080 & 0.5146 & 0.5841 & 0.5803 & 0.5915 & 0.6247 & 0.6097 & 0.6186 & 0.6366 \\
\hline H26 & 0.8396 & 0.8401 & 0.8362 & 0.8098 & 0.8434 & 0.8177 & 0.8247 & 0.8257 & 0.8275 \\
\hline H27 & 0.0831 & 0.0835 & 0.1056 & 0.0921 & 0.0833 & 0.1044 & 0.0726 & 0.0745 & 0.0783 \\
\hline
\end{tabular}

\section{Analysis and conclusions}

It can be seen that the level of informatization between different industries is different. For example, the informatization level of communication equipment, computer and other electronic equipment manufacturing industry is fluctuating, but it is always in the first of all industries. The informatization of the transportation equipment manufacturing industry is also at a high level, and shows a strong growth momentum. The performance of heavy industry, especially equipment manufacturing, is better than light industry. The information level of most industries shows a growth trend, such as agricultural and sideline products processing industry, but there are exceptions, the textile industry, black metal smelting and rolling industry have good information level, but the decline trend is obvious. In addition, some industries experienced a different level of decline in the level of information between 2012 and 2014, which is related to the domestic economic situation. 


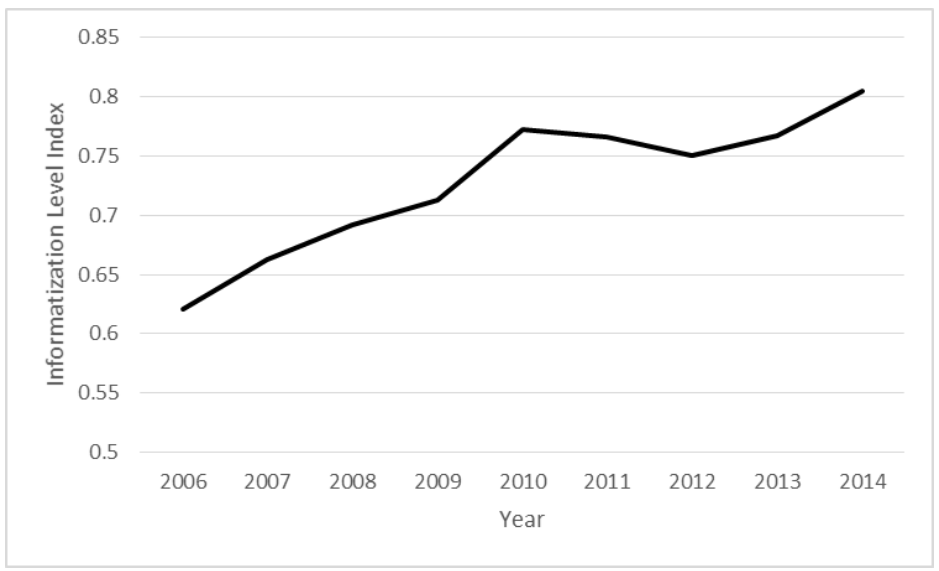

Fig. 2 -Informatization Level of the Transportation Equipment Manufacturing Industry

This paper analyses the panel data of 27 manufacturing industries from 2006 to 2014 . According to the above conclusions, the construction of informatization should be further strengthened. The construction of informatization should be carried out from two aspects of supply and demand. While strengthening the ability of industry to produce information, the ability of industry to use information should be cultivated.

\section{References}

1. W.He, X.Xia, Review of the Study on the Measurement of Informatization Standard and the Contribution of it to Economic Growth, J. Mar. Journal of Chongqing Institute of Technology. 20 (2006) 108-112.

2. R. Stroh, M.I. Chunra, Cyberspace: It is the conceptual landscape of information disquisition groups products and services that anyone can access when they log onto an online information service, J. Oct. Telecommunications. 10 (1996) 27-30.

3. W.Zheng, Comparative analysis of the degree of regional economic informatization, J.Jan. Quantitative \& Technica Economics. 1 (2001) 27-29.

4. X.Hu, An empirical study on the differences of regional informatization in China, J. May. Research on Financial and Economic Issues. 5 (2003) 73-78.

5. G.Xu, S.Zhao, Layer-by-layer Analysis on Economic Structures Effect of Informatization in China, J. July. China Industrial Economy. 7 (2004) 21-28.

6. W.He, Research on the Level and Changing Trend of China Industry's Informatization, J. Appl. Science of Science and Management of S.\& T. 4 (2006) 59-64.

7. X.Han, N.Hui, Can Informatization Improve Technology Innovation Efficiency of Chinese Industrial Sectors, J. Dec. China Industrial Economics. 12 (2014) 70-82. 